\title{
Voces de la ausencia/poética de la memoria en la obra Evidencias (2010) de Norberto Puzzolo, Museo de la Memoria, Rosario, Argentina. Sonido, silencio e imagen durante la dictadura argentina (1976-1983)
}

\section{Voices of absence/Poetics of memory in the installation "Evidencias" (2010) of Norberto Puzzolo, Museum of memory, Rosario, Argentina. Sound, silence and image during the dictatorship in Argentina (1976-1983)}

TIPO DE TRABAJO: Comunicación virtual.

PALABRAS CLAVE

Instalación, visualidad, sonoridad, memoria, política, Argentina.

KEY WORDS

Instllation, Visuality, Sonority, Memory-politics, Argentina.

RESUMEN

Este trabajo se propone analizar los diversos planos puestos en relación a partir del sonido y la visualidad con las poéticas de la memoria a partir de la obra Evidencias (2010) del artista argentino Norberto Puzzolo (Rosario,1948) realizada para el Museo de la Memoria de la ciudad de Rosario, Santa Fe, Argentina . Esta obra trata una doble problemática. Por una parte, expone los trágicos hechos de apropiación de niños, hijos de detenidos desaparecidos por el terrorismo de Estado instaurado por la dictadura militar entre 1976 y 1983. Por otro lado, muestra la ardua búsqueda de las Abuelas de Plaza de Mayo y la restitución de la identidad a sus nietos. La inmaterialidad, la capacidad evocadora de lo sonoro como una dimensión de las emociones, de las huellas de presencias arrebatadas de un tiempo pasado, se propone como un punto de partida para la reflexión sobre el pasado de la historia reciente argentina, una historia en constante revisión y re-construcción.

\section{ABSTRACT}

This work intends to analyze the various plans put in relationship from the sound and Visuality with the poetics of memory from the work evidences (2010) of the Argentine artist Norberto Puzzolo (Rosario, 1948) made for the Museum of the memory of the City of Rosario, Santa Fe, Argentina. This work is a double problem. On the one hand, it exposes the tragic acts of appropriation of children arrested missing by State terrorism established by the military dictatorship between 1976 and 1983. On the other hand, shows the arduous search for the Grandmothers of Plaza de Mayo and the restitution of identity to their grandchildren. Immateriality, the evocative capacity of sound as a dimension of emotions, of traces of snatched presences of a time past, is proposed as a starting point for reflection on the past in the recent history of argentina, a story in constant review and re-construction. 


\section{INTRODUCCIÓN}

La cualidad inmaterial del sonido- así como su capacidad evocadora de emociones, de las huellas de presencias arrebatadas de un tiempo pasado-, se propone como un punto de partida para la reflexión sobre cómo el arte contemporáneo elabora un tema controvertido de la historia argentina de la segunda mitad del siglo XX: la apropiación de niños durante el terrorismo de Estado instaurado por la dictadura militar en Argentina (1976-1983). En este trabajo se propone analizar la obra Evidencias (2010) del artista rosarino Norberto Puzzolo (1943) ubicada en el Museo de la Memoria de Rosario, Provincia de Santa Fe, Argentina. Se trata de un sitespecific cuyo desafío estético parte de la inexistencia de imágenes sobre las que el artista aspiraba a componer una imagen visual.

Como consecuencia de la apropiación ilegal de los bebés nacidos en Centros Clandestinos de Detención y de aquellos niños y niñas de corta edad secuestrados junto a sus padres luego desaparecidos, estos niños no solo perdieron a sus familias sino también les fue arrebatada su propia identidad, identidad que fue entonces sustituida por la de sus apropiadores. En consecuencia, la obra presentó un gran desafío para Puzzolo: realizar una obra visual desde la carencia de imágenes materiales. No obstante, el artista quien en los años sesenta había desarrollado su obra en el marco del conceptualismo, se abocó a la obra desde esa imposibilidad material y a partir de la idea de que las imágenes no solo existen en su medio concreto sino que también perviven en la memoria de quienes las evocan.

La propuesta de Norberto Puzzolo abre un camino para una reflexión sobre un espacio estético en tránsito, inestable, a través de la desintegración o mutación de las imágenes con los que trabaja. Desde esta perspectiva, se re-elabora la memoria histórica y se recomponen los imaginarios para estructurar el presente.

\section{METODOLOGÍA}

La metodología empleada en este estudio se ha basado en la consulta de la documentación bibliográfica sobre la obra que se encuentra en el Museo de la Memoria de la ciudad de Rosario, el arte contemporáneo y sonoro y los estudios sobre historia reciente. La base para la obra reposa en el Archivo Biográfico Familiar de Abuelas de Plaza de Mayo que recaba información sobre la historia de vida de los detenidos-desaparecidos durante la última dictadura cívico-militar instaurada en Argentina en 1976, con el fin de transmitírsela a los nietos, hijos de los desaparecidos.En esta línea de análisis, desde un enfoque interdisciplinario, se plantea una aproximación a la instalación cuya pregunta por cómo se reconstruyen las miradas sobre la historia nacional, la identidad y la memoria se sostiene en datos concretos que surgen del archivo de Abuelas. Al mismo tiempo, esta obra utiliza como elemento estético central la inmaterialidad de la dimensión sonora para construir significados.

\section{CONTENIDO}

Evidencias (2010)

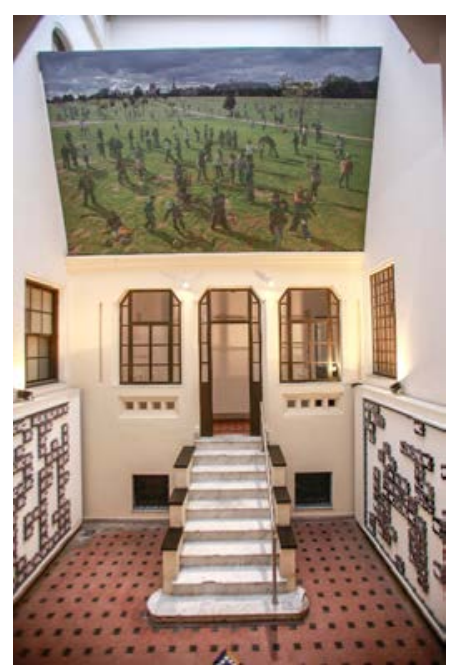

Figura1. Norberto Puzzolo, Evidencias, 2010. Museo de la Memoria de Rosario. Fuente: Museo de la Memoria de Rosario 
Alcino, Valeria Fabiana

Voces de la ausencia/poética de la memoria en la obra Evidencias (2010) de Norberto Puzzolo, Museo de la Memoria, Rosario, Argentina. Sonido, silencio e imagen durante la dictadura argentina (1976-1983)

IV Congreso INTERNACIONAL DE INVESTIGACIÓN EN ARTES VISUALES ANIAV 2019

IMAGEN [N] VISIBLE]

http://dx.doi.org/10.4995/ANIAV.2019.9164

En el Museo de la Memoria de Rosario la instalación en proceso Evidencias (fig. 1) del artista Norberto Puzzolo (Rosario, 1948) conmemora el acto de la búsqueda así como también la recuperación de las identidades robadas de los niños nacidos en los centros clandestinos de detención, hijos de los detenidos desaparecidos; nietos apropiados durante la última dictadura militar (1976-1083).

En 1974 muere Juan Domingo Perón durante su tercer y conflictivo gobierno. Le sucede quien era su esposa y vicepresidente, María Estela Martínez de Perón. La incapacidad de gobernar y las tensiones sociales que se instalaron en Argentina y dentro de un contexto internacional favorable a los gobiernos militares en América del Sur, allanaron el camino a quienes tomaron el poder por la fuerza de las armas el 24 de marzo de 1976, comenzando la más férrea dictadura cívico-militar del Cono Sur. Con el fin de desactivar los focos subversivos y el avance de la izquierda, se instaló el autodenominado "Proceso de Reorganización Nacional" a cargo de la Junta Militar encabezada por el Comandante General del Ejército Jorge Rafael Videla, seguido del Comandante General de la Marina Emilio Eduardo Massera y el de aviación, Brigadier General Orlando Ramón Agosti.

Como eje central del plan de gobierno -alineado con el Plan Cóndor-, el objetivo primordial era eliminar al "enemigo interno" y a su estructura familiar. La amenaza constante provocó que muchos documentos, fotografías e imágenes se destruyeran o escondieran. En consecuencia, la época estuvo atravesada por el terror y el control de las imágenes. No resulta casual que artistas comprometidos políticamente que habían trabajado en obras de fuerte impacto político abandonaran la actividad artística, se exiliaran o que algunos artistas conceptualistas se refugiaran en la seguridad de la pintura figurativa al óleo.

Entre 1976 y 1978 los frecuentes secuestros y torturas se sistematizaron; se organizaron maternidades clandestinas y redes de apropiación de los niños que allí nacieron que perduraron hasta el fin de la dictadura. Aquellos niños perdieron no solo a sus familias biológicas que seguían con vida, sino también sus identidades sustituidas por la de sus apropiadores. En este contexto, las imágenes de los niños están ausentes, no existen. Algunos niños muy pequeños fueron llevados con sus padres detenidos y apropiados. De ellos hay alguna imagen de aquella época, conservadas como tesoros en el seno de la familia que los busca.

Con el regreso a la democracia en 1983, el Dr. Raúl Alfonsín inició el Juicio a las Juntas y se organizó la búsqueda de los desaparecidos y de sus hijos a través de un banco de datos de ADN y del equipo de Antropología Forense con el fin de restituir las verdaderas identidades, estableciéndose como inalienable el derecho a la identidad. La búsqueda de los nietos generó la Asociación Abuelas de Plaza de Mayo donde se organiza el banco de datos y las búsquedas tanto de las abuelas o familiares como de los propios jóvenes que sospechan de su origen.

En1977, en plena dictadura, conscientes de la posibilidad de que sus hijos hubiesen sido asesinados, se creó la Asociación Abuelas de Plaza de Mayo con el fin de localizar a los hijos de los hijos secuestrados y desaparecidos, nacidos en maternidades clandestinas como la ESMA (Escuela de Mecánica de la Armada) y el Pozo de Banfield, entre otros. Se consideran desaparecidos más de 500 nietos, apropiados por familias diversas, entregados a orfanatos como NN o vendidos. En 1998 se fundó la Casa de Abuelas de Plaza de Mayo, en un edificio que había funcionado como Centro Clandestino de Detención y Exterminio. La Casa es un espacio dedicado a la promoción del derecho a la identidad.

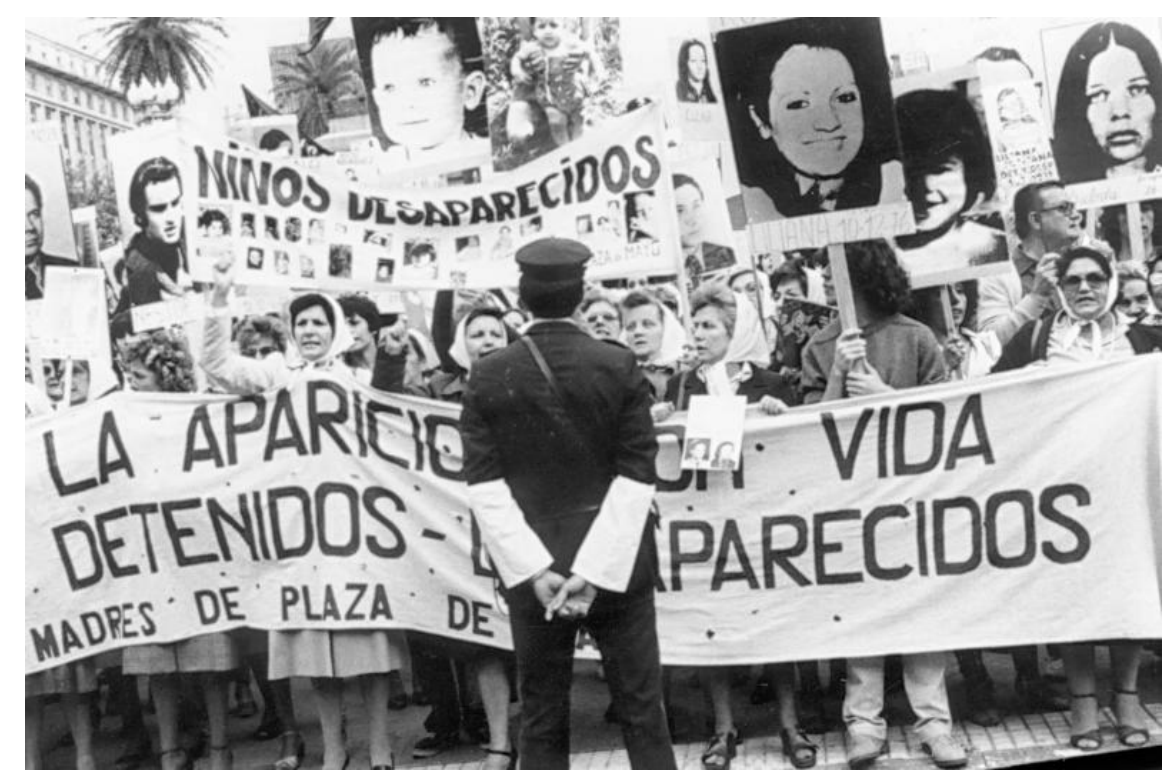

Figura 2. Las Abuelas no tienen miedo. Lo peor que podía pasarles ya pasó. Sus voces desafían al régimen militar que sigue negando la existencia de los desaparecidos. FUENTE: ABUELAS, FECHA: 24.03.1980 
Alcino, Valeria Fabiana

Voces de la ausencia/poética de la memoria en la obra Evidencias (2010) de Norberto Puzzolo, Museo de la Memoria, Rosario, Argentina. Sonido, silencio e imagen durante la dictadura argentina (1976-1983)

IV Congreso INTERNACIONAL DE INVESTIGACIÓN EN ARTES VISUALES ANIAV 2019

IMAGEN [N] VISIBLE]

http://dx.doi.org/10.4995/ANIAV.2019.9164

Al organizarse en 2010 el Museo de la Memoria de Rosario en un edificio que funcionó como sede del II Comando del Ejército, fueron convocados varios artistas entre los que se encontraba Norberto Puzzolo. Actualmente dedicado a la fotografía, había formado parte del Grupo de Artistas de Vanguardia de Rosario y había participado en el mítico Tucumán Arde de 1968.

En la elaboración de la obra, el artista se ha encontrado con la dificultad de la ausencia de imágenes, imágenes destruidas inexistentes materialmente pero presentes en la memoria colectiva. Hay algo intangible, inmaterial que existe en ese número de nietos buscados, quinientos bebés apropiados como "botín de guerra" o quizás [n] ya que varios han perdido a sus familiares para que los busquen. No hay imágenes, pero existen las voces de quienes los continúan buscando. Aquí la dimensión sonora prevalece sobre la imagen.

Evidencias se encuentra en un patio andaluz del antiguo edificio donde hoy funciona el Museo. En el centro de este espacio hay una fuente en forma de estrella revestida con coloridos mosaicos. Puzzolo buscó recuperar la fuente como elemento lúdico relacionada con el juego de los niños en las plazas, alrededor de las fuentes. A partir de este elemento se organiza la instalación. Asimismo, se presenta un video y en las paredes laterales, dos tableros que contienen cerca de doscientos dispositivos móviles con forma de fichas de rompecabezas. (Fig.2) Cada pieza representa a cada uno de los niños apropiados; "El contenido de las mismas es información recabada en el archivo de la Asociación civil Abuelas de Plaza de Mayo". (Museo de la Memoria de Rosario, 2010)

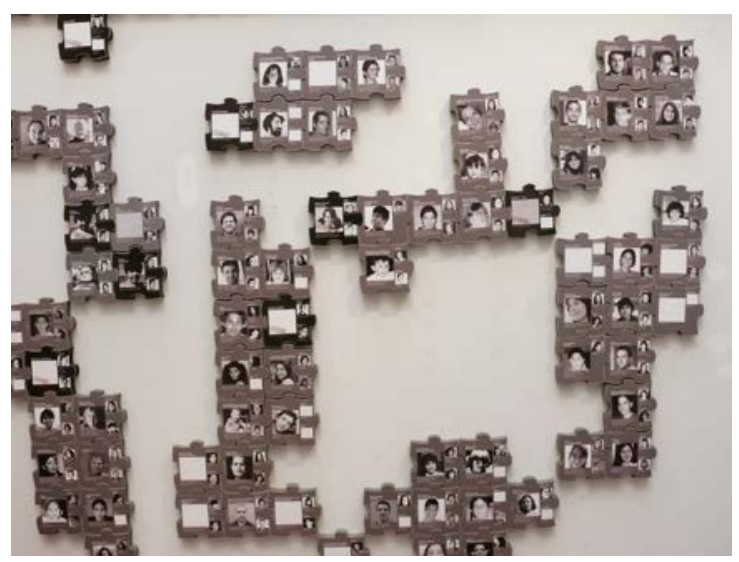

Figura 3. Norberto Puzzolo, Evidencias, 2010, Museo de la Memoria de Rosario. Fuente: Museo de la Memoria de Rosario.

En otro plano, aparece la banda sonora realizada por Lisandro Puzzolo que resulta fundamental. Se trata de la grabación de una voz femenina. Esta voz, con el mismo tono que caracterizaba a los modos en que las maestras de escuela primaria tomaban lista, pero de "un modo mecánico y repetitiva, casi mecánica lo que crea una sensación de agobio" (Lauría, 2013), va mencionando cada nombre que se encuentra escrito en las fichas del rompecabezas. Son los nombres de los nietos, hijos de los desaparecidos. A este llamado, responden ausente, no está; cuando la expectativa general es escuchar la voz de un niño contestando presente. La evidencia de los crímenes de lesa humanidad está allí, en el vacío dejado por los niños apropiados. La banda sonora establece una conexión emotiva entre el espectador y la representación visual.

Como sostiene la curadora Adriana Lauría, esta es una obra que "está en permanente situación de cambio"(ivi). Cada 10 de diciembre, cuando se celebra la vuelta a la democracia en Argentina, las piezas del rompecabezas "migran de una pared a otra, de la pared de los buscados a la pared de los recuperados" (ivi). Así, paulatinamente, se va recomponiendo la trama de las piezas faltantes tanto en la pared del rompecabezas como en el conjunto de la sociedad (fig.4).

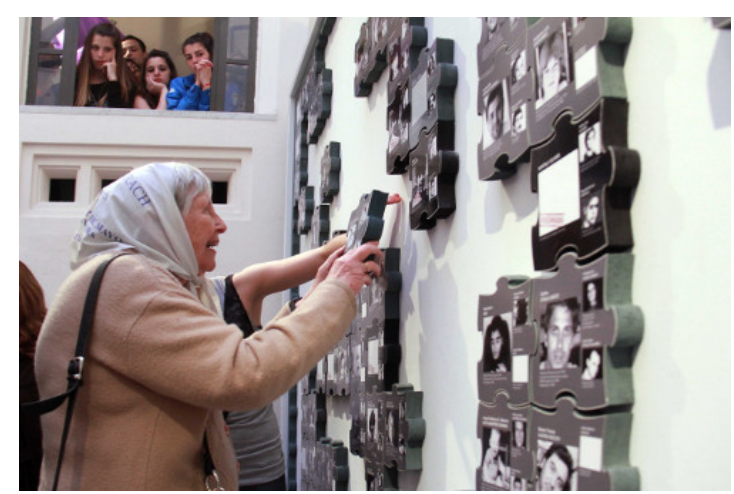

Figura 4. Acto de restitución de identidades, 2014. Fuente: Museo de la Memoria Rosario 

silencio e imagen durante la dictadura argentina (1976-1983)

IV Congreso INTERNACIONAL DE INVESTIGACIÓN EN ARTES VISUALES ANIAV 2019 IMAGEN [N] VISIBLE]

http://dx.doi.org/10.4995/ANIAV.2019.9164

El nombre de la instalación es una "evidencia" concreta de los crímenes de lesa humanidad cometidos durante la dictadura argentina. Más allá de las dudas instauradas por el propio sistema político, generando dudas sobre el paradero de los desaparecidos y sus hijos, la ausencia de imágenes y el proceso de recuperación de cada nieto identificado y restituido ya en su adultez a su familia de origen, $\mathrm{o}$ bien en sentido inverso, la restitución de la verdadera identidad a cada nieto, surge de voluntades encontradas. Esas voluntades se construyeron sobre la falta, sobre las imágenes desvanecidas por el tiempo pero presentes en la memoria. La obra cuestiona la precaria tranquilidad de las conciencias y haciendo evidente las ausencias, las voces silenciadas, abre un espacio dinámico que permite reconstruir la historia argentina reciente.

En la búsqueda de memoria, verdad y justicia para el pueblo argentino, en ese acto aquellos nietos son nombrados. El sonido de su nombre, involucra a la vez, la tensión entre ausencia y presencia. En sus nombres enunciados, se restituye la voz inaudible de los desaparecidos. En la instalación de Norberto Puzzolo, el sonido se ubica como una evocación del pasado en tanto que el aspecto visual instala el tiempo presente y futuro. En esta unión de poéticas y temporalidades, emerge el interrogante del ser social nacional.

\section{CONCLUSIONES}

En este trabajo se ha partido de una obra que pone en juego temporalidades distintas, pero de alto impacto político en el seno de la sociedad argentina. La elaboración de representaciones de problemáticas surgidas del contexto social y político vinculados a la memoria y a la identidad se conjuga con la dificultad de la inexistencia de imágenes. Puzzolo, elabora una reflexión sobre la memoria histórico-política nacional así como también responde a una demanda social que intenta reponer identidades individuales a aquella identidad colectiva: "los nietos". Junto a ello, la antítesis entre sobreexposición de imágenes que habita nuestro presente y la ausencia de las imágenes que dejó la dictadura militar de 1976 ha dado lugar a la elaboración de los hechos políticos de una manera estética que reposa en la inmaterialidad de lo sonoro como potencia de significación poética. Desde este punto, se ha intentado abordar la relación entre la materialidad de la obra visual y la inmaterialidad/invisibilidad del sonido. La dimensión sonora como medio evocativo de múltiples temporalidades: pasado/presente; pasado/futuro; presente/futuro. Pensar el sonido como un signo de presencia/ausencia en esas temporalidades, como signo de aquello que en un tiempo venidero podrá -o no- estar presente. La dimensión histórica/política y política/social enfrentando la tensión entre memoria/olvido, ha resultado central en este abordaje.

\section{FUENTES REFERENCIALES}

AA.VV. Asociación civil Abuelas de Plaza de Mayo, https://www.abuelas.org.ar/

Divinzenso, M. A. y Scocco, M. (2017). Ejército y política: Rosario durante los primeros años del II Cuerpo de Ejército, 1960-1966. En Aguila, G. (Dir.). Territorio ocupado: Ia historia del II Cuerpo de Ejército en Rosario: 1960-1990. Rosario: Editorial Municipal.

Lauría, A. (2014). Norberto Puzzolo. Paisajes de la memoria. Catálogo de Arte, San Juan, Provincia de San Juan, Museo Provincial de Bellas Artes Franklin Rawson. Disponible en https://issuu.com/museofranklinrawson/docs/catalogo puzzolo -festival de la luz

Lauría, A. (2012). Entrevista con el artista Norberto Puzzolo, Buenos Aires, inédita. Disponible en veartetv https://youtu.be/rT6LCMoRgal

Museo de la Memoria de Rosario http://www.museodelamemoria.gob.ar/page/obra/id/1/Puzzolo\%2C-Norberto/Evidencias

Puzzolo, N. (2010). Evidencias. Instalación en proceso. Paneles: 21,21 x 4, 20 m / fichas de 17 x17 cm / 1 gigantografía 5,45 x 3 m., Nro. registro: 993770, Donación del artista. Rosario, Museo de la Memoria de Rosario. http://norbertopuzzolo.com.ar/\#!/ 